\title{
Aprendizagem baseada em jogos: experiência no ensino de Física
}

\author{
Isadora A. M. do Nascimento, Quezia A. de Sousa, Edicarlos M. Batista, Messias \\ Vilbert de S. Santos, Francisco Genivan Silva \\ Instituto Federal de Educação, Ciência e Tecnologia do Rio Grande do Norte - Campus \\ Avançado Parelhas (IFRN) \\ Parelhas - RN - Brasil \\ \{isadoraazevedo23,s.quezia.a,edicarlos047\}@gmail.com, messias.vilbert, \\ genivan.silva\}eifrn.edu.br
}

\begin{abstract}
Game-Based Learning has developed a reputation among educators and is perceived as an attractive form of supplementary learning, with potential to provide improvements in the educational process, covering different levels of education. This article presents an experience report about the use of games for the teaching of physics. The study was conducted among high school students to verify the potential of this resource to implement improvements in teaching and learning. At the end of the study, there was good acceptance of the activities by the student body, increase of income, as well as positive results regarding the assimilation of contents and student participation.
\end{abstract}

Resumo. A Aprendizagem Baseada em Jogos desenvolveu uma reputação entre os educadores, sendo percebida como uma forma atrativa de aprendizagem suplementar, com potencial de proporcionar melhorias no processo educacional, abrangendo os diferentes níveis de ensino. Este artigo apresenta um relato de experiência quanto ao uso de jogos para o ensino da física. O estudo foi realizado entre estudantes do ensino médio para verificar $o$ potencial deste recurso para implementar melhorias no ensino $e$ aprendizagem. Ao fim do estudo, verificou-se boa aceitação das atividades pelo corpo discente, aumento de rendimento, bem como resultados positivos no que diz respeito a assimilação dos conteúdos e participação dos alunos.

\section{Introdução}

Com o desenvolvimento acelerado de tecnologias, percebe-se, naturalmente, uma crescente ascensão de aspectos relativos à ciência da computação no convívio social. No que concerne ao âmbito educacional, essa realidade não é diferente, sendo possível verificar a potencialidade de vários conhecimentos relacionados a área tecnológica para $\mathrm{o}$ melhoramento do processo de ensino, como por exemplo no uso de jogos eletrônicos e da gamificação [Medeiros et al. 2018].

Muitas são as estratégias e ações desenvolvidas ao longo dos últimos anos na educação com a perspectiva de suprir carências e aprimorar o processo de ensino através ou com ajuda da computação. $\mathrm{O}$ uso de jogos educacionais tem se tornado mais comum, principalmente, para o ensino de matemática e ciências [Hainey et al. 2016]. Para 
VIII Congresso Brasileiro de Informática na Educação (CBIE 2019)

Anais do XXV Workshop de Informática na Escola (WIE 2019)

Pietruchinski et al. (2011), os jogos são ferramentas capazes de auxiliar no processo educativo, desde que sejam planejados e trabalhados de uma forma crítica, que possibilite a aprendizagem de uma maneira significativa ao aprendiz.

Nesta perspectiva, conforme Prensky (2012), a aprendizagem baseada em jogos está de acordo com as necessidades e os estilos de aprendizagem da geração atual e das futuras gerações. É motivadora, divertida e versátil, capaz de ser adaptada a quase todas as disciplinas, informações ou habilidades, mas só acontece quando tanto o envolvimento quanto a aprendizagem são altos. E, devido às suas características inerentes, tais como competição, desafio, interação, feedback, entre outras, eles podem transformar a aprendizagem em uma experiência envolvente, motivadora e divertida.

Conforme demonstrado por Medeiros e Medeiros (2002), a física qualifica-se como uma disciplina que, ao englobar diferentes conceitos, denota alta complexidade e abstração. Comumente, são encontradas barreiras para o desenvolvimento pleno da área, dado que, boa parte dos discentes, apresentam desinteresse e desmotivação quanto às metodologias habituais empregadas para o ensino.

Por conseguinte, compreendendo a necessidade de avaliação de novas metodologias para o ensino de matérias regulares, este artigo refere-se à um relato de experiência do uso de jogos eletrônicos para complementar o ensino de física. $\mathrm{O}$ estudo foi efetivado com alunos do nível médio em uma escola de ensino médio técnico. Em uma perspectiva geral, a experiência fundamentou-se na realização de oficinas em três turmas da instituição, nas quais foram empregados jogos e simulações para explanação de conceitos físicos.

Por meio das atividades, que apresentavam como objetivo principal investigar e analisar as potencialidades e efeitos de uma metodologia baseada no uso de jogos para a disciplina física, encontraram-se resultados positivos quanto à aceitação da abordagem e absorção de conteúdos propostos pelo público observado.

\section{Uso de jogos na educação}

Como demonstrado por Ramos (2014), as diretrizes dos Parâmetros Curriculares Nacionais (1977) admitem como um dos objetivos do ensino básico "o aluno ser capaz de resolver problemas, utilizando o pensamento lógico, $[\ldots]$, selecionando a sequência de ações para resolver o problema [...]". Portanto, consegue-se compreender que aprimorar os processos de ensino, adequando-os às perspectivas sociais atuais, configura-se como um pilar para o desenvolvimento pleno do que se entende por ensino essencial.

Nesse sentido, Kapp (2012, p.7) define jogo como "um sistema em que os jogadores se envolvem em um desafio abstrato, definido por regras, interatividade e feedback, que resulta em um resultado quantificável, muitas vezes provocando uma reação emocional". Na definição de Kapp, o jogo não está completamente separado das regras da realidade, pois imita situações e procedimentos da vida real. Não apenas os jogadores no conceito de Kapp interagem com o sistema, mas também entre si e com o conteúdo do jogo. Sendo assim, é possível antecipar as contribuições que as diversas ramificações dessa área podem proporcionar para o processo de ensino/aprendizagem de disciplinas como a física. 
Especificamente, no que diz respeito à física, de acordo com Viana et al. (2015, p.2) é por meio desta que os alunos devem ser "capazes de interpretar fenômenos e processos naturais, situando e dimensionando a interação do ser humano com a natureza como parte da própria natureza em transformação". Nessa perspectiva, verifica-se a exigência de certa autonomia e capacidade de visualização e ação dos discentes sobre a compreensão dos fenômenos abordados pela disciplina, o que pode ser relacionado as características da aprendizagem mediada por jogos. Como demonstrado por Costa e Verdeaux (2016), a dinâmica apresentada por um jogo consegue moldar os desafios às habilidades do jogador, incentivando a realização de uma determinada tarefa com eficiência.

Logo, ponderando sobre os fatos citados anteriormente, é possível considerar uma convergência entre o ensino/aprendizagem da física auxiliado por meio de aspectos da ciência da computação, uma vez que, retomando ideias de Bordini et al. (2017) e Blikstein (2008) apud Santana (2017), estes favorecem a motivação, a criatividade e a produtividade.

\section{Metodologia}

O presente estudo utilizou como método de pesquisa o relato de experiência de caráter qualitativo. A experiência descrita realizou-se nas dependências de uma escola de ensino médio técnico e teve como população de estudo uma amostra dos discentes da referida instituição, participantes dos cursos técnicos integrados em informática e mineração.

Essencialmente, as atividades realizadas relacionaram-se a promoção de oficinas, nas quais foram empregados diferentes jogos para desenvolvimento de uma aula de física. A pesquisa como um todo organizou-se em 5 fases distintas com diferentes propósitos, as quais estão identificadas e especificadas abaixo.

- Fase I - Aplicação de formulário diagnóstico que levantou dentre o corpo discente as principais dificuldades e predileções com relação à aprendizagem de física.

- Fase II - Elaboração de planos de ensino e dos testes que constituíram as oficinas. Basicamente, os assuntos tratados foram cinemática e leis de Newton; eletrostática e constituintes da matéria.

- Fase III - Aplicação de pré-teste para verificação do conhecimento prévio dos estudantes com relação aos assuntos que seriam abordados durante as oficinas.

- Fase IV - Separação dos grupos por turma para aplicação dos tratamentos (metodologias de ensino) e execução das oficinas.

- Fase V - Aplicação de pós-teste e análise da situação de ensino-aprendizagem entre os estudantes e entre os grupos; análise da aceitação dos jogos e das metodologias propostas.

As atividades foram empreendidas com as turmas de informática $2^{\circ}$ ano (Vespertino), mineração $3^{\circ}$ ano (Vespertino) e informática $3^{\circ}$ ano (Matutino) que, no presente artigo, são nomeadas, respectivamente, como turmas 1, 2 e 3 . As oficinas, que apresentaram uma duração de, aproximadamente, 2 horas cada, compreendiam a mesma 
VIII Congresso Brasileiro de Informática na Educação (CBIE 2019)

Anais do XXV Workshop de Informática na Escola (WIE 2019)

dinâmica, havendo utilização de jogos e explanação complementar dos conceitos físicos pelo professor responsável.

Durante as oficinas, foram empregadas três ferramentas distintas para trabalhar aspectos da disciplina de física, dentre as quais duas eram jogos e uma configurou-se como material complementar, uma vez que se tratava de um quiz. Estes materiais integram o projeto $\mathrm{PhET}$ Simulações Interativas da Universidade de Colorado Boulder.

Inicialmente, pretendia-se selecionar diversos jogos relacionados a física e, em seguida, com auxílio do professor da disciplina, definir quais assuntos poderiam ser trabalhados. Entretanto, após pesquisa realizada nas principais plataformas digitais, como Play Store, Apple Store e Google, por meio de palavras chaves relacionadas a temáticas da física, foram encontrados poucos aplicativos que realmente se enquadrassem como jogos, constatando-se que, entre os avaliados, a grande maioria qualificava-se como quizzes ou apenas tangenciavam conceitos da disciplina. Logo, a escolha das ferramentas foi condicionada por indicação da plataforma $\mathrm{PhET}$ pelo docente especialista na área.

A partir do primeiro jogo, denominado "Módulo de pouso lunar", conseguiu-se trabalhar conceitos relacionados a cinemática e leis de Newton, mais especificamente, velocidade, aceleração, vetores, lei da inércia e ação e reação. De modo análogo, por meio do segundo jogo, "Hóquei no campo elétrico", e do quiz "Monte um átomo", foram explanados aspectos referentes ao conteúdo de eletrostática, detalhando tópicos como a constituição do átomo e sua estabilidade e a interação entre cargas.

Basicamente, as atividades realizadas apresentaram o mesmo progresso, incluindo a utilização de diferentes recursos. Inicialmente, foram aplicados os pré-testes relativos ao conteúdo da aula e logo em seguida houve a explicação do conteúdo e utilização dos jogos. Durante o processo, foram fornecidos 20 minutos para familiarização dos alunos com o jogo e em seguida mais 15 minutos para que estes o utilizassem efetivamente. Por fim, os discentes foram convidados a refazer os testes iniciais e a avaliar a experiência como um todo.

Contudo, é importante ressaltar que existiram diferenças quanto a ordem das atividades realizadas no decorrer da oficina, de modo a possibilitar diferentes análises. Estas variações ocorreram de acordo com as turmas e estão detalhadas abaixo.

- Turma 1: Utilização a priori do jogo "Módulo de pouso lunar" e explanação do conteúdo.

- Turma 2: Explicação do conteúdo, com a utilização de ferramentas auxiliares (quiz), e aplicação do jogo "Hóquei no campo elétrico".

- Turma 3: Utilização a priori de um jogo, explanação do conteúdo, aplicação do segundo jogo e desenvolvimento do conteúdo referente a este.

Como citado anteriormente, ao final de cada oficina foi fornecido aos alunos um questionário para avaliação dos jogos, o qual foi baseado nos modelos desenvolvidos por Savi et al. (2011) e por Martins et al. (2016). O formulário era composto por 26 afirmativas sobre três subescalas (motivação, experiência do usuário e aprendizagem) subdivididas em dez dimensões (atenção, relevância, confiança e satisfação, imersão, desafio, competência, divertimento, interação social e aprendizagem), as quais poderiam 
VIII Congresso Brasileiro de Informática na Educação (CBIE 2019)

Anais do XXV Workshop de Informática na Escola (WIE 2019)

ser avaliadas por meio de 5 valores, $-2,-1,0,1,2$, que representavam, respectivamente, discordância total, discordância, indiferença, concordância e concordância total.

\section{Resultados e discussões}

Por meio da experiência descrita neste artigo, foi possível a obtenção de dados quanto as perspectivas relacionadas ao ensino da física e o uso de jogos, os quais podem ser subdivididos em três dimensões principais, que se referem à disciplina abordada pelo projeto em específico, a aprendizagem e a aplicação da metodologia.

Previamente, por meio de formulário eletrônico, realizou-se entre os alunos da escola uma pequena pesquisa sobre ensino da física, de modo a identificar as percepções dos estudantes quanto a essa ciência. No total, foram obtidas 77 respostas, as quais representavam, majoritariamente, discentes com idades entre 15 e 18 anos que já haviam cursado a disciplina.

Quanto à experiência com a física, 76,6\% dos alunos consultados afirmaram possuir alguma dificuldade na disciplina e $70,1 \%$ consideraram que a principal complexidade da matéria estava relacionada à aspectos matemáticos. Esses indicadores demonstram que, dentro da visão do corpo discente, existem certos empecilhos para o desenvolvimento completo do processo de ensino/aprendizagem não só no que diz respeito a ciência da natureza em questão, como também da própria matemática.

Além disso, ao serem questionados sobre as diferentes formas de abordagem utilizadas no âmbito da disciplina e a aprendizagem individual, apenas 18,2\% dos estudantes indicaram preferência por uma metodologia mais habitual, voltada para questões conceituais e fundamentadas no uso de quadro, livro e projetor. Por conseguinte, com base nos dados encontrados, reforça-se a ideia da necessidade de métodos e materiais suplementares mais atrativos, visto que processos mais dinâmicos e inovadores poderiam, provavelmente, amenizar a resistência verificada entre a maioria dos discentes e incentivar a participação destes nas atividades, melhorando o entendimento geral da disciplina.

No que diz respeito as oficinas, estas foram realizadas em três turmas com, respectivamente, 19,18 e 20 alunos, totalizando 57 discentes. Inicialmente, foram aplicados pré-testes, que poderiam ser pontuados entre 0 e 100 pontos, de modo a verificar o conhecimento prévio dos participantes para nível de comparação. Do total de testes recolhidos, considerou-se apenas 56, uma vez que, na turma 1 , um não apresentava respostas.

Como demonstrado pela tabela 1 abaixo, averiguou-se certa discrepância entre as turmas, dado que os desempenhos dos participantes foram bastante diferentes, mesmo existindo conhecimento anterior dos conceitos tratados.

Tabela 1. Porcentagem equivalente a pontuação atingida no pré-teste

\begin{tabular}{|c|c|c|c|}
\hline \multirow{2}{*}{ PONTUAÇÃO ATINGIDA } & \multicolumn{3}{|c|}{ PORCENTAGEM DE ALUNOS } \\
\cline { 2 - 4 } & Turma 1 & Turma 2 & Turma 3 \\
\hline Entre 0 e 25 pontos & $44,4 \%$ & $11,1 \%$ & $35,0 \%$ \\
\hline Entre 26 e 50 pontos & $55,6 \%$ & $50,0 \%$ & $30,0 \%$ \\
\hline Entre 51 e 75 pontos & $0,0 \%$ & $38,9 \%$ & $25,0 \%$ \\
\hline
\end{tabular}


VIII Congresso Brasileiro de Informática na Educação (CBIE 2019)

Anais do XXV Workshop de Informática na Escola (WIE 2019)

\begin{tabular}{|c|c|c|c|}
\hline Entre 76 e 100 pontos & $0,0 \%$ & $0,0 \%$ & $10,0 \%$ \\
\hline
\end{tabular}

Na turma 1, por exemplo, conforme a tabela 1, todos os estudantes obtiveram notas menores ou iguais a metade do valor atribuído a avaliação. Semelhantemente, na turma 2, apenas 38,9\% atingiram uma pontuação superior a 50 pontos. Em contrapartida, na turma 3, consoante aos percentuais exibidos, observa-se claramente uma distribuição muito mais homogênea entre os componentes do grupo, encontrando-se inclusive notas acima dos 75 pontos.

Ao analisar-se os três resultados em conjunto, constata-se que a média geral entre os participantes foi de, aproximadamente, 40,8 pontos, e que 29 participantes obtiveram nota abaixo desse valor. Desse modo, assim como nos dados analisados na fase I da pesquisa, pode-se indicar a presença de déficits no processo de aprendizagem da física, sendo possível presumir a existência de problemas quanto à comunicação entre a disciplina e os alunos, os quais podem estar relacionados a questões como motivação.

Em momento posterior a realização das oficinas, os participantes do estudo foram convidados a responder novamente, se desejassem, os testes. Do total de alunos considerados (56), apenas 24, 8 em cada grupo, modificaram alguma das respostas. Contudo, apesar da pequena participação, pôde-se perceber resultados consideráveis, existindo aumento das notas iniciais em até 75 pontos. A comparação entre a notas obtidas pelos alunos que realizaram o pós-testes, 24 ao total, estão apresentadas abaixo. Vale destacar que para essa interpretação só foram consideradas as notas absolutas no teste final e não a diferença entre as pontuações das duas avaliações.

Tabela 2. Porcentagem equivalente a pontuação atingida no pós-teste

\begin{tabular}{|c|c|c|c|}
\hline \multirow{2}{*}{ PONTUAÇÃO ATINGIDA } & \multicolumn{3}{|c|}{ PORCENTAGEM DE ALUNOS } \\
\cline { 2 - 4 } & Turma 1 & Turma 2 & Turma 3 \\
\hline Entre 0 e 25 pontos & $25,0 \%$ & $0,0 \%$ & $0,0 \%$ \\
\hline Entre 26 e 50 pontos & $75,0 \%$ & $0,0 \%$ & $25,0 \%$ \\
\hline Entre 51 e 75 pontos & $0,0 \%$ & $50,0 \%$ & $12,50 \%$ \\
\hline Entre 76 e 100 pontos & $0,0 \%$ & $50,0 \%$ & $62,5 \%$ \\
\hline
\end{tabular}

Apesar de ser necessário considerar que há uma maior retenção de conhecimentos quando estes são recém-apresentados, a partir desses dados, consegue-se reconhecer que há um grande potencial na utilização dos jogos, uma vez que por meio desta tornou-se possível explanar aspectos importantes da disciplina, de modo que os alunos conseguiram compreender os fenômenos e os conceitos. Ademais, pode-se ainda salientar que, esse resultado, reforça a ideia de que a abordagem utilizada contribuiu para um ganho dos conhecimentos fundamentais dentro dos conteúdos explanados.

Para avaliação dos jogos, como citado anteriormente, foram utilizados questionários que compreendiam 26 afirmações relacionadas a 10 aspectos. Desse modo, após as oficinas foram recolhidos um total de 57 formulários avaliativos, dos quais apenas 49 foram considerados válidos. Dentre as turmas 1, 2 e 3, respectivamente, foram obtidas, 17, 15 e 17 avaliações completas. Os gráficos abaixo apresentam os resultados alcançados em cada turma de acordo com os critérios disponibilizados. 
VIII Congresso Brasileiro de Informática na Educação (CBIE 2019)

Anais do XXV Workshop de Informática na Escola (WIE 2019)

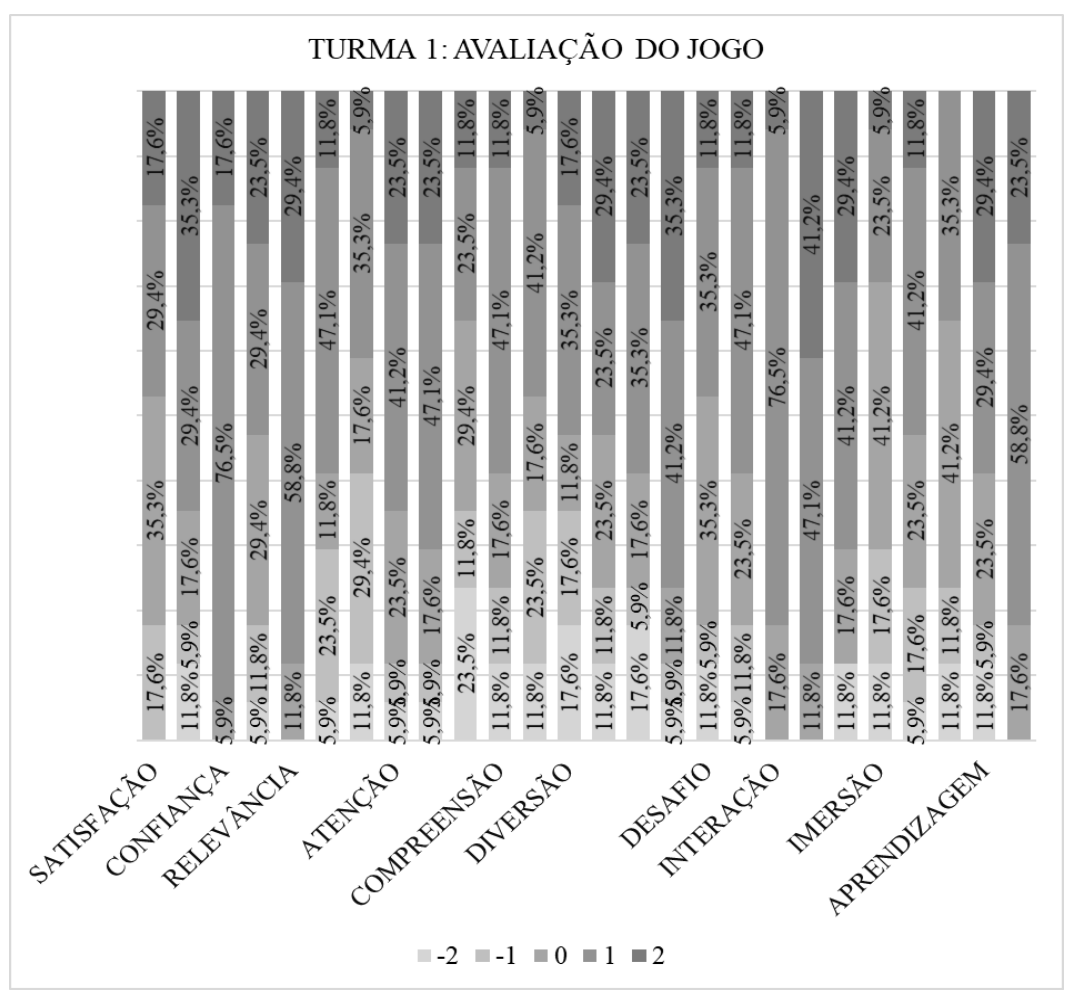

Gráfico 1. Avaliação da turma 1 quanto ao jogo utilizado durante a oficina.

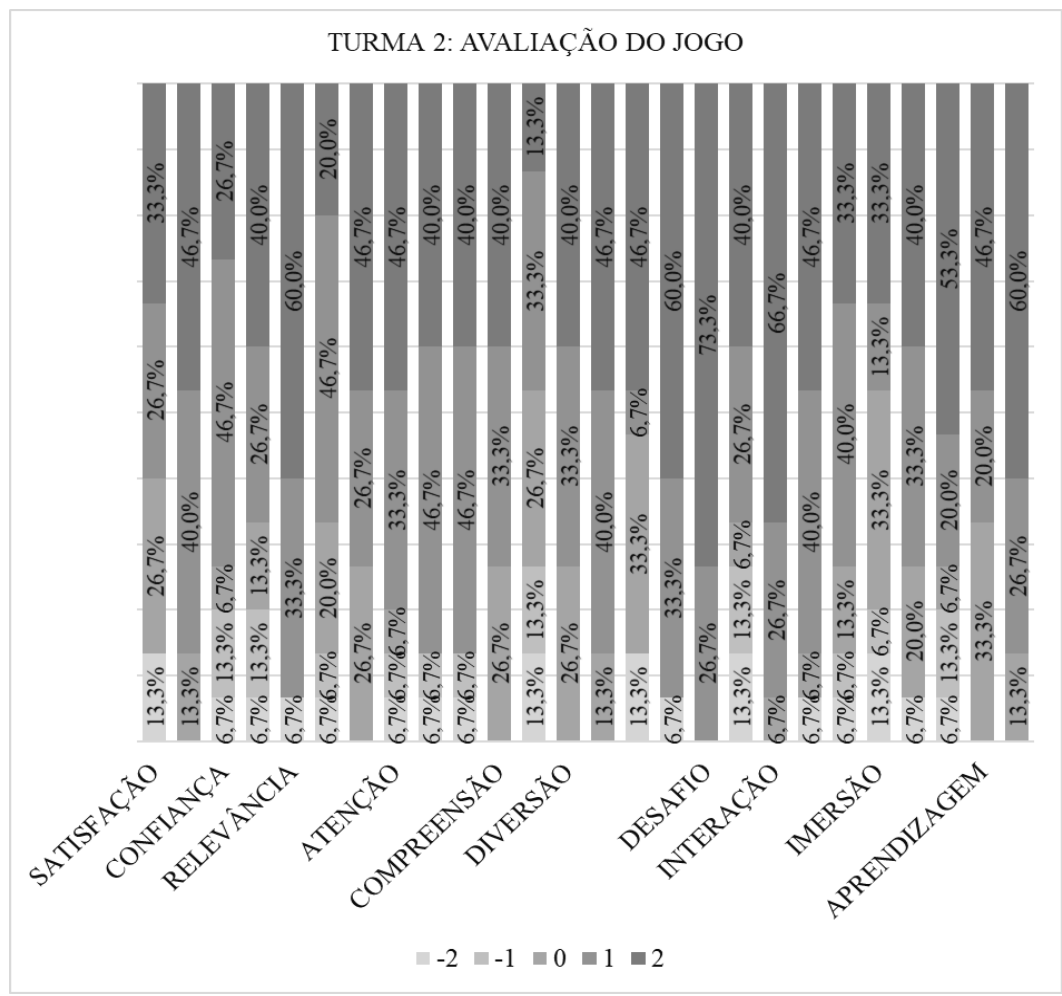

Gráfico 2. Avaliação da turma 2 quanto ao jogo aplicado durante a oficina. 
VIII Congresso Brasileiro de Informática na Educação (CBIE 2019)

Anais do XXV Workshop de Informática na Escola (WIE 2019)

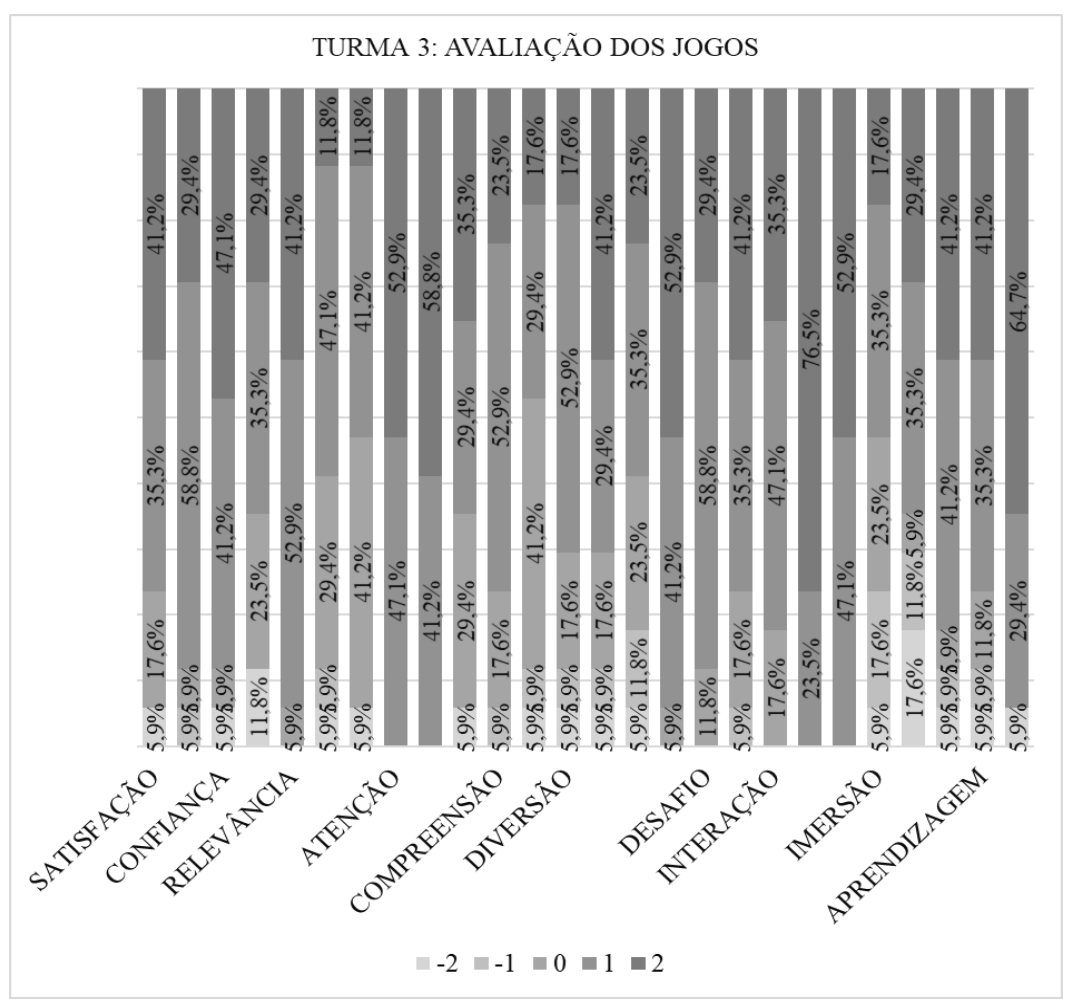

\section{Gráfico 3. Avaliação da turma 3 quanto aos dois jogos utilizados durante a oficina.}

Em uma comparação geral dos dados apresentados nos gráficos acima, na categoria motivação, que engloba as dimensões atenção, relevância, confiança e satisfação, obteve-se uma aprovação expressiva dentre as respostas dos participantes, demonstrando um bom progresso dos jogos quanto à aspectos como desempenho pessoal e evolução.

Mais especificamente, no tópico satisfação, observa-se que as turmas 2 e 3 demonstraram melhores avaliações, o que pode indicar uma maior conexão entre as perspectivas dos alunos e o jogo "Hóquei no campo elétrico". Diferentemente, o grupo 1 demonstrou um posicionamento menos favorável, indicando menor engajamento por parte destes com relação ao jogo "Módulo de pouso lunar".

No que diz respeito a seção relacionada a experiência do usuário (imersão, desafio, competência, divertimento e interação social), a avaliação das turmas, novamente, manteve-se favorável, o que indica um desempenho significativo dos jogos em aspectos como desafio e diversão. Entretanto, assim como na categoria motivação, percebe-se uma melhor aceitação do jogo "Hóquei no campo elétrico". No caso da turma 3, que foi exposta aos dois jogos, percebe-se uma aproximação muito maior da avaliação correspondente a turma 2, sendo possível supor que a experiência com o jogo relacionado ao hóquei influenciou a avaliação do último grupo.

Além disso, averiguou-se que vários alunos demonstraram interesse nos jogos. Entre o total de participantes da oficina, aproximadamente $69 \%$ concordaram que recomendariam o jogo a outros colegas e, por volta de $65 \%$, consentiram que gostariam de utilizar as ferramentas apresentadas em outro momento. 
Com relação a última categoria de avaliação, a qual referia-se à percepção de aprendizagem por meio dos jogos, as três turmas expressaram, majoritariamente, concordância total (valor 2 na avaliação) quanto a contribuição destes para 0 aprendizado dentro da disciplina, sendo importante destacar que, como nas outras seções, a turma 1 manifestou menor nível de aprovação. Entretanto, constatou-se que, apesar de concordarem com a contribuição dos jogos, os alunos demonstraram um posicionamento neutro expressivo quanto à comparação da metodologia aplicada e outras atividades da disciplina.

Em uma análise mais abrangente, identifica-se que de modo geral o jogo "Hóquei no campo elétrico" obteve melhores avaliações do que o jogo "Módulo de pouso lunar". Este padrão pode estar relacionado as próprias características das ferramentas, uma vez que o primeiro apresentava fases diferentes, que evoluíam em nível de dificuldade, propiciando maior desafio e diversão aos alunos. Além disso, a metodologia empregada durante as oficinas que aplicaram este jogo pode ter influenciado nos resultados, dado que o uso integrado de uma ferramenta extra chamada "Monte um átomo" estimulou a atenção dos discentes, que buscaram respondê-lo corretamente.

O outro jogo, diferentemente, apesar de dispor de um design mais completo, também exigia um entendimento mais complexo, característica que pode ter contribuindo para uma avaliação menos favorável. Quanto ao desafio e variação, a ferramenta não apresentava diversificação em níveis, o que, em algumas perspectivas, diminui a sensação de engajamento e relevância para os alunos.

\section{Considerações finais}

A experiência demonstrada no presente artigo buscou destacar a relevância do uso de algumas ramificações da ciência da computação para educação por meio da realização de oficinas voltadas para o ensino da física, fundamentadas em uma metodologia baseada na utilização de jogos.

Mediante os resultados encontrados, é possível identificar que as atividades realizadas propiciaram uma experiência positiva para os alunos, uma vez que estes foram apresentados a um contexto fora do habitual para o ensino da disciplina. Além disso, consegue-se ainda reconhecer perspectivas animadoras dentro da ideia de aprendizagem, posto que, com base na visão dos próprios discentes, os recursos utilizados favoreceram o desenvolvimento de aspectos como diversão e desafio, os quais acarretam em uma participação mais expressiva nas aulas.

Ainda assim, mesmo considerando que a experiência colaborou amplamente para a compreensão dos conceitos físicos pelos alunos, identifica-se a necessidade de experimentos mais completos, que envolvam uma maior quantidade de participantes e diferentes conteúdos, de modo a observar os impactos da metodologia a longo prazo e sanar as limitações encontradas durante o experimento. Consequentemente, consegue-se distinguir espaço para projetos futuros, inclusive com outras disciplinas regulares.

\section{Referências}

Bordini, A. et al. (2017) "Pensamento Computacional nos ensinos fundamental e médio: uma revisão sistemática", In: Congresso brasileiro de informática na educação, 6. , 
VIII Congresso Brasileiro de Informática na Educação (CBIE 2019)

Anais do XXV Workshop de Informática na Escola (WIE 2019)

2017, Recife. Anais do XXVIII Simpósio Brasileiro de Informática na Educação. Recife: Sociedade Brasileira de Computação. p. 123-132.

Costa, T.; Verdeaux, M. (2016) "Gamificação de materiais didáticos: uma proposta para a aprendizagem significativa da modelagem de problemas físicos", Experiências em ensino de ciências, Brasília, v. 11, n. 2, p.60-105.

Hainey, T., Connolly, T. M., Boyle, E. A., Wilson, A., e Razak, A. (2016) "A systematic literature review of games-based learning empirical evidence in primary education". Computers \& Education, 102, $202-223,2016 . \quad$ DOI: 10.1016/j.compedu.2016.09.001

Kapp, K. M. (2012) The Gamification of Learning and Instruction: Game-based Methods and Strategies for Training and Education, 1st Edition, Pfeiffer.

Martins, R.; Reis, R.; Marques, B. (2016) "Inserção da programação no ensino fundamental: Uma análise do jogo Labirinto Clássico da Code.org através de um modelo de avaliação de jogos educacionais", In: Congresso brasileiro de informática na educação, 5., 2016, Uberlândia. Anais do XXII Workshop de Informática na Escola. Uberlândia: Sociedade Brasileira de Computação, p. 121-130.

Medeiros, A.; Medeiros, C. F. (2002) "Possibilidades e limitações das simulações computacionais no ensino da física", Revista Brasileira de Ensino de Física, São Paulo, v. 24, n. 2, p.77-86.

Medeiros, T. et al. (2018). "Um Mapeamento e Avaliação de Jogos Digitais para Ensino de Matemática". Anais do III Congresso Sobre Tecnologias na Educação (CTRL+E 2018), Fortaleza/CE, p. $381-391$.

Pietruchinski, M., Coelho Neto, J., Malucelli, A. e Reinehr, S. (2011), "Os jogos educativos no contexto do SBIE: uma revisão sistemática de literatura". In: Congresso brasileiro de informática na educação. Anais do XXII Simpósio Brasileiro de Informática Educacional. Aracaju/SE: Sociedade Brasileira de Computação, p.476485

Prensky, M. (2012). Aprendizagem Baseada em Jogos Digitais. São Paulo: Senac.

Ramos, H. (2014) "Pensamento Computacional na Educação Básica: uma proposta de aplicação pedagógica para alunos do quinto ano do Ensino Fundamental do Distrito Federal". Monografia (Licenciatura) - Curso de Computação, Departamento de Ciência da Computação, Universidade de Brasília, Brasília.

Santana, A. et al. (2017) "Tem Ideia na Rede: Inserindo o Pensamento Computacional na Rede Municipal de Ensino", In: Congresso brasileiro de informática na educação, 6., 2017, Recife. Anais XXIII Workshop de Informática na Escola. Recife/PE: Sociedade Brasileira de Computação, p. 1032-1041.

Savi, R. et al. (2010) "Proposta de um Modelo de Avaliação de Jogos Educacionais", Renote, Porto Alegre, v. 8, n. 3, p.1-12.

Viana, L. H. et al. (2015) "Tecendo novos métodos de ensino e avaliação: utilizando o Game Angry Birds Rio no ensino de Física”, In: Encontro de iniciação à docência da UEPB, 5., 2015, Campina Grande. Anais... Campina Grande: Realize. 